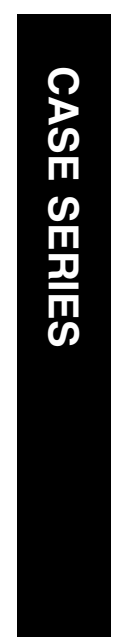

\section{Switching biologic agents for uveitis}

\begin{abstract}
Purpose To observe whether switching between biological agents helps to gain or maintain uveitis remission in cases with sight-threatening refractory uveitis.

Methods We reviewed the case notes of seven patients with refractory uveitis, who had switched between biological agents. The switch between biological agents (infliximab or adalimumab) was for gaining control of systemic symptoms, uveitis, or for the ease of administration.

Results There were three adults (one each with sarcoidosis, ankylosing spondylites, and sero-negative polyarthropathy) and four children with juvenile idiopathic arthritis. The adults were switched twice between the various biological agents to gain adequate control of their systemic disease or to ease administration of the drug. All the children were switched to a second biological agent for gaining uveitis remission. Following the final switch, the concomitant immunosuppression in all the patients either reduced or remained unchanged, and only two patients remained on additional prednisolone (10 $\mathrm{mg} /$ day). Conclusions Our case series provides preliminary evidence that in cases of refractory uveitis with loss of initial clinical response to one biological agent, switching to another agent can restore control of intraocular inflammation. In addition, switching helps to control systemic symptoms and allows ease of administration.

Eye (2009) 23, 1868-1870; doi:10.1038/eye.2009.203; published online 31 July 2009
\end{abstract}

Academic Unit of Ophthalmology, Bristol Eye Hospital, Bristol, UK

Correspondence: N Dhingra, Bristol Eye Hospital, Lower Maudlin Street, Bristol, BS1 2LX, UK. Tel: + 44117928 4563; Fax: +44117925 1421 . E-mail: ndhingra@ doctors.org.uk

Received: 8 April 2009 Accepted in revised form: 6 July 2009

Published online: 31 July 2009

Financial support: None.
Keywords: uveitis; biologics; infliximab; adalimumab

\section{Introduction}

Since their discovery in the 1990s, biologic drugs ${ }^{1}$ have been used to treat uveitis refractory to traditional immunosuppressants. Many questions on their use though have remained unanswered; particularly when to initiate therapy, which agent and at what dosage to use, and for how long the treatment should continue. ${ }^{2}$ In the event of failure of desired response to one biologic therapy, the efficacy of switching from infliximab to adalimumab has been well described in other diseases, such as rheumatoid arthritis. ${ }^{3}$ Switching between biologic agents has been done either for primary (poor response) or secondary failure (development of side effects or loss of effect secondary to human anti-chimera antibody development). ${ }^{4}$ There is little evidence that switching between biologics helps to gain or maintain uveitis remission.

As part of an overall audit programme of immunomodulation for uveitis, we reviewed the case notes of seven patients with sightthreatening, refractory uveitis treated with biologic agents (Tables 1 and 2). Our series uses the standardised uveitis nomenclature $(\mathrm{SUN})^{5}$ grading system using the same outcomes to assess disease activity and measure efficacy as the ability to withdraw concomitant immunosuppression and/or reduction of prednisolone dose to below $10 \mathrm{mg} /$ day. SUN grading refers to a standardised system in which AC cells are graded in a slit beam measuring $1 \times 1 \mathrm{~mm}$ in size. The score is given as a number of cells in the field $(0<1$ cell, $0.5+$ for $1-5$ cells, $1+$ for $6-15$ cells, $2+$ for $16-25$ cells, $3+$ for $26-50$ cells and $4+$ having $>50$ cells). The vitreous haze was graded using the National Eye Institute system using binocular indirect ophthalmoscope referred as BIO score, ${ }^{6}$ where score 0 is given for absence of cells, 0.5 for presence of occasional cells, 1 where posterior pole is clearly visible, 2 for slightly hazy details, 3 for very hazy details, 4 for barely visible details, and 5 is where the details are not visible.

\section{Case 1}

Patient 1 had sarcoid-related uveitis with bilateral disc oedema and choroidal neovascularisation necessitating alemtuzumab 
Table 1 Patient profile and switch agent used

\begin{tabular}{|c|c|c|c|c|c|c|c|c|}
\hline$P t$ & Sex & $\begin{array}{c}\text { Age at } \\
\text { presentation }\end{array}$ & Diagnosis & 1st drug & Reason for switch & $2 n d$ drug & Reason for switch & $3 r d d r u g$ \\
\hline 1 & $\mathrm{~F}$ & 46 & Sarcoidosis & Alemtuzumab & Persistent uveitis & Infliximab & Difficult venous access & Adalimumab \\
\hline 2 & $\mathrm{~F}$ & 33 & A spondylites & Infliximab & Side effects & Adalimumab & Persistent uveitis & Infliximab \\
\hline 3 & $\mathrm{~F}$ & 4 & JIA & Infliximab & Psoriasis flare-up & Adalimumab & Worsening of joints & Infliximab \\
\hline 4 & $\mathrm{M}$ & 5 & JIA & Infliximab & Persistent uveitis & Adalimumab & & \\
\hline 5 & $\mathrm{~F}$ & 2 & JIA & Infliximab & Persistent uveitis & Adalimumab & & \\
\hline 6 & $\mathrm{~F}$ & 5 & JIA & Infliximab & Persistent uveitis & Adalimumab & & \\
\hline 7 & $\mathrm{~F}$ & 13 & Idiopathic & Infliximab & Persistent uveitis & Adalimumab & & \\
\hline
\end{tabular}

Abbreviations: AC, anterior chamber; BIO, bioscore; JIA, juvenile idiopathic arthritis; VA, visual acuity (Log Mar); RE, right eye; LE, left eye; BE, both eyes; NA, patient did not have second switch; phaco, phacoemulsification of lens; vity, vitrectomy; PDT, photodynamic therapy; MTX, methotrexate; MMF, mycophenolate mofetil; Tac, tacrolimus; pred, prednisolone; Concom IMT, concomitant immunomodulation therapy.

Table 2 Patient disease activity with biologic switch agent

\begin{tabular}{|c|c|c|c|c|c|c|c|c|c|c|c|c|c|c|c|c|}
\hline \multirow[t]{2}{*}{$P t$} & \multirow{2}{*}{$\begin{array}{c}\text { Initial } V A \\
R E, L E\end{array}$} & \multirow{2}{*}{$\begin{array}{l}\text { Final VA } \\
R E, L E\end{array}$} & \multicolumn{4}{|c|}{$\begin{array}{l}\text { AC } \\
\text { grade }\end{array}$} & \multicolumn{4}{|c|}{$\begin{array}{l}\text { BIO } \\
\text { Score }\end{array}$} & \multirow[t]{2}{*}{$\begin{array}{c}\text { Additional } \\
\text { events }\end{array}$} & \multicolumn{4}{|c|}{$\begin{array}{l}\text { Concom } \\
\text { IMT }\end{array}$} & \multirow[t]{2}{*}{$\begin{array}{l}\text { Last Biologic } \\
(\mathrm{m})\end{array}$} \\
\hline & & & Initial & $\begin{array}{c}1 s t \\
\text { switch }\end{array}$ & $\begin{array}{l}\text { 2nd } \\
\text { switch }\end{array}$ & Final & Initial & $\begin{array}{l}1 s t \\
\text { switch }\end{array}$ & $\begin{array}{l}2 n d \\
\text { switch }\end{array}$ & Final & & Initial & $\begin{array}{c}1 \text { st } \\
\text { switch }\end{array}$ & $\begin{array}{l}2 n d \\
\text { switch }\end{array}$ & Final & \\
\hline 1 & $1.0,1.60$ & $0.8,0.8$ & 0,0 & 0,0 & $0.5,0$ & 0,0 & $0.5,0$ & $0.5,0$ & 1,1 & 0,0 & $\begin{array}{l}\text { BE Phaco/vity, } \\
\text { RE PDT }\end{array}$ & $\begin{array}{l}\text { Tac, Pred } \\
(15 \mathrm{mg})\end{array}$ & $\begin{array}{l}\text { Tac, Pred } \\
(20 \mathrm{mg})\end{array}$ & $\begin{array}{l}\text { Tac, Pred } \\
(30 \mathrm{mg})\end{array}$ & $\begin{array}{l}\text { Tac, Pred } \\
(10 \mathrm{mg})\end{array}$ & 24 \\
\hline 2 & $0.18,0.18$ & $0.18,0.18$ & 1,0 & 0,0 & $0.5,0$ & 0,0 & 0,0 & 0,0 & 1,1 & 0,0 & RE amblyopia & MTX & MTX & MTX & MTX & 12 \\
\hline 3 & $0.18,0.30$ & $0.18,0.18$ & 2,1 & 1,0 & 0,0 & 1,0 & 0,0 & NR & 0,0 & 0,0 & $\begin{array}{c}\text { Post fossa } \\
\text { medulloblastoma } \\
\text { BE Phaco }\end{array}$ & MTX, Etan & MTX & MTX & MTX & 9 \\
\hline 4 & $0.0,0.0$ & $0.0,0.0$ & $0.5,0.5$ & 2,3 & NA & 1,1 & 0,0 & 0,0 & NA & 0,0 & - & MTX & MTX MMF & & MMF & 9 \\
\hline 5 & $0.30,0.48$ & $0.0,0.18$ & 1,1 & 1,2 & NA & 0,0 & 2,1 & 0,1 & NA & 0,0 & - & MTX & MTX & & MTX & 6 \\
\hline 6 & $0.0,-0.10$ & $0.0,-0.20$ & $0.5,0$ & 0,0 & NA & 1,0 & 0,0 & 0,0 & NA & 0,0 & - & $\begin{array}{l}\text { MMF MTX Pred } \\
\quad(10 \mathrm{mg})\end{array}$ & $\begin{array}{l}\text { MMF, Pred } \\
\quad(10 \mathrm{mg})\end{array}$ & & MMF & 5 \\
\hline 7 & $0.0,0.60$ & $0.0,0.76$ & 0,0 & 0,0 & NA & $0,0.5$ & 0,0 & 1,1 & NA & 0,0 & $\begin{array}{l}\text { Chronic disc } \\
\text { swelling }\end{array}$ & $\begin{array}{l}\text { MMF Tac, } \\
\text { Pred }\end{array}$ & $\begin{array}{l}\text { MMF Pred } \\
\quad(10 \mathrm{mg})\end{array}$ & & $\begin{array}{l}\text { MMF Pred } \\
(7.5 \mathrm{mg})\end{array}$ & 6 \\
\hline
\end{tabular}

Abbreviations: AC, anterior chamber; BIO, bioscore; JIA, juvenile idiopathic arthritis; VA, visual acuity (Log Mar); RE, right eye; LE, left eye; BE, both eyes; NA, patient did not have second switch; phaco, phacoemulsification of lens; vity, vitrectomy; PDT, photodynamic therapy; MTX, methotrexate; MMF, mycophenolate mofetil; Tac, tacrolimus; pred, prednisolone; Concom IMT, concomitant immunomodulation therapy. 
(campath-1H) and photodynamic therapy. Two years after campath- $1 \mathrm{H}$ induction of remission, intravenous infliximab therapy ( $5 \mathrm{mg} / \mathrm{kg}$ every 8 weeks) was introduced. Although the uveitis was well controlled with infliximab, she was switched to adalimumab (40 mg every 2 weeks), 4 months later because of difficult venous access. A similar report of three patients with Behcet's disease has shown maintained disease control after switching of biologics. ${ }^{7}$

\section{Case 2}

Patient 2 had ankylosing spondylitis with prolonged anterior uveitis and cystoid macular oedema, nonresponsive to topical and oral steroids. She developed severe side effects with mycophenolate mofetil and tacrolimus and was therefore commenced on infliximab ( $5 \mathrm{mg} / \mathrm{kg}$ every 8 weeks for maintenance). After 10 infliximab infusions, the patient developed cholestasis, necessitating cholecystectomy. Although this side effect was not thought to

be related to the biologic agent, infliximab was discontinued and patient was switched to subcutaneous adalimumab therapy ( $40 \mathrm{mg}$ every 2 weeks). As the uveitis flared up again, the patient was switched back to infliximab therapy and has since been in remission. A recent study by Rudwaleit et $a l^{8}$ showed that adalimumab had a substantial preventive effect on anterior uveitis flares in patients with active ankylosing spondylites including patients with a recent history of anterior uveitis flares.

\section{Case 3}

Patient 3 had psoriasis, sero-negative arthropathy and sight-threatening uveitis. The intraocular inflammation was initially well controlled on infliximab for 9 months. However, the psoriasis worsened considerably and the treatment was switched to adalimumab. Four months later, though the uveitis remained in remission, her psoriasis and the joints disease further worsened and she was switched back to infliximab. The psoriasis, joints, and the uveitis has been stable for over the last 9 months.

\section{Cases $4-7$}

In patients 4-7 with juvenile idiopathic arthritis, switching from infliximab to adalimumab has helped to achieve and maintain uveitis remission. It has also facilitated ease of administration for patient and family and reduced concomitant therapy in three patients.

\section{Discussion}

Why patients should respond to one biologic agent and not another, despite similar mechanisms of action, remains unexplained. The various possible hypotheses include differential bioavailability of these drugs and the development of anti-drug antibodies. ${ }^{9}$

All the patients in our cohort used the first biologic agent for a mean of 12 months (range, 8-24 months); thereby indicating that it was secondary failure. The cause of this secondary failure is unknown and so are the predictive factors and the clinical and therapeutic strategies to avoid such situations.

Our case series provides preliminary evidence that in cases of refractory uveitis with loss of initial clinical response to one biologic agent, switching to another agent can restore control of intraocular inflammation especially in cases with juvenile idiopathic arthritis. In adult patients, switching helped in gaining systemic disease remission and helped in ease of administration of the drug.

\section{References}

1 Dick AD, Isaacs JD. Immunomodulation of autoimmune responses with monoclonal antibodies and immunoadhesins: treatment of ocular inflammatory disease in the next millennium. Br J Ophthalmol 1999; 83(11): 1230-1234.

2 Imrie F, Dick AD. Biologics in the treatment of uveitis. Curr Opin Ophthalmol 2007; 18: 481-486.

3 Hyrich KL, Lunt M, Dixon WG, Watson K D, Symmons DPM. Effects of switching between anti-TNF therapies on HAQ response in patients who do not respond to their first anti-TNF drug. Rheumatology 2008; 47: 1000-1005.

4 van Vollenhoven RF. Switching between anti-tumour necrosis factors: trying to get a handle on a complex issue. Ann Rheum Dis 2007; 66: 849-851.

5 Jabs DA, Nussenblatt RB, Rosenbaum JT. Standardization of uveitis nomenclature for reporting clinical data. Results of First International Workshop. Am J Ophthalmol 2005; 140(3): 509-516.

6 Nussenblatt RB, Palestine AG, Chan CC, Roberge F. Standardization of vitreal inflammatory activity in intermediate and posterior uveitis. Ophthalmology 1985; 92(4): 467-471.

7 Mushtaq B, Saeed T, Situnayake RD, Murray PI. Adalimumab for sight-threatening uveitis in Behcet's disease. Eye 2007; 21: 824-825.

8 Rudwaleit M, Rødevand E, Holck P, Vanhoof J, Kron M, Kary $\mathrm{S}$, Kupper H. Adalimumab effectively reduces the rate of anterior uveitis flares in patients with active ankylosing spondylitis: results of a prospective open-label study. Ann Rheum Dis 2009; 68(5): 696-701.

9 Haraoui B. Is there a rationale for switching from one antitumor necrosis factor agent to another? J Rheumatol 2004; 31: 1021-1022. 